This item was submitted to Loughborough's Research Repository by the author.

Items in Figshare are protected by copyright, with all rights reserved, unless otherwise indicated.

\title{
Activation schemes of synthetic inertia controller on full converter wind turbine (type 4)
}

PLEASE CITE THE PUBLISHED VERSION

http://dx.doi.org/10.1109/PESGM.2015.7286430

PUBLISHER

(C) IEEE

VERSION

AM (Accepted Manuscript)

\section{PUBLISHER STATEMENT}

This work is made available according to the conditions of the Creative Commons Attribution-NonCommercialNoDerivatives 4.0 International (CC BY-NC-ND 4.0) licence. Full details of this licence are available at: https://creativecommons.org/licenses/by-nc-nd/4.0/

\section{LICENCE}

CC BY-NC-ND 4.0

\section{REPOSITORY RECORD}

Gonzalez-Longatt, Francisco M.. 2019. "Activation Schemes of Synthetic Inertia Controller on Full Converter Wind Turbine (type 4)". figshare. https://hdl.handle.net/2134/17687. 


\title{
Activation Schemes of Synthetic Inertia Controller on Full Converter Wind Turbine (Type 4)
}

\author{
Francisco M. González-Longatt \\ School of Electrical, Electronic and System Engineering \\ Loughborough University \\ Loughborough, United Kingdom \\ fglongatt@fglongatt.org
}

\begin{abstract}
One of the challenges in future energy systems is the massive use of high power converters that decouple new energy sources from the AC power grid, disabling natural frequency response. This situation decreases the total system inertia affecting the ability of power system to overcome system frequency's disturbances. It has been established by the wind power industry a controller to enable inertial response on wind turbines generators (WTG) enabling the frequency response: Artificial, Emulated, Simulated, or Synthetic Inertia. However, there is a clear lack of knowledge about activation scheme used for these controllers and how they work in practical manner. This paper proposes three activation schemes for synthetic inertia on WTG based on full converters: (i) Continuously Operating triggering, (ii) Under-frequency Trigger and (iii) Maximum-Frequency Gradient Trigger. Simulations over a test system are used for a preliminary evaluation of the proposed activation schemes. The main contribution of this paper is the three schemes to activate the synthetic inertia controller and the simulations results that demonstrate under-frequency trigger provides good dynamic response.
\end{abstract}

Index Terms-- Frequency controller, frequency stability, power system, protection scheme, wind turbine generator.

\section{INTRODUCTION}

Future energy systems will look completely different to the power systems on nowadays [1], [2]. High and low power converters will be massively deployed almost everywhere into on the electric network [3], [4], [5] and for very different use: (i) high power interfaces of the renewable energy produced by highly variable generators, (ii) interface of several technologies for energy storage, each one with very different time constants, and (iii) interconnecting several synchronized power systems, creating an Pan-European transmission network which facilitate the massive integration of large-scale renewable energy sources and the balancing and transportation of electricity markets. The high/low power converters typically tend to decouple energy sources from the pre-existent AC power systems [2, 5]. During a system frequency disturbance (SFD) the generation/demand power balance is lost, the system frequency will change at a rate initially determined by the total system inertia $\left(H_{T}\right)$ [6]. However, future power systems will increase the installed power capacity (MVA) but the effective system inertial response will stay the same nowadays [2]. The result is deeper frequency excursions of system disturbances.

There are several good papers [7], [8], [9], and technical reports [10], [11], [12] dealing with theory [13], [14], [15], modelling [16] and simulation [8], [17] of inertial response of wind turbine generators (WTG) and some of them provide general ideas about possible impacts on power systems and there effects on transient under-frequency response [18], [19], [20]. Even some controls strategies have been proposed to mitigate the impact of reduced inertia [21]. However, there is lack of knowledge about control schemes used to activate the synthetic inertia.

This aim of this paper is to propose and to evaluate activation schemes of synthetic inertia controller on full converter wind turbine (FCWT). The paper is organized as follows. Section II introduces the concept of synthetic inertia and presents releasing "hidden" inertia controller. Section III proposes three activation schemes for the synthetic inertia: (i) Continuously Operating, (ii) Under-frequency Trigger and (iii) Maximum-Frequency Gradient Trigger. Section III the simulations results are used to assess the impact of the proposed activation schemes on the system frequency response and electro-mechanical variables on the WTG. The main contributions of this paper are: (a) three schemes to activate the synthetic inertia controller and (b) a preliminary assessment of these schemes. Simulations results on a test system demonstrates under-frequency trigger provide good dynamic response. Finally, the advantages/disadvantages of the activation schemes are discussed in Section IV.

\section{SYNTHETIC INERTIA}

Modern WTGs use power electronics converters to enable variable speed operation in order to capture wind energy over a wide range of speeds. However, power converter isolates 
the rotational speed from the system frequency so WTG based on back-to-back $\mathrm{AC} / \mathrm{DC} / \mathrm{AC}$ converters offer no natural response to system frequency [9], [16]. The WT industry has created several controllers for modern WTG's in order to provide inertial response (and governor response on some cases) for large frequency deviation for, short-duration: Artificial, Emulated, Simulated, or Synthetic Inertial. Examples of synthetic inertia controlled commercially available for WTG are: General Electric WindINERTIA ${ }^{\text {TM }}$ [23], [24], ENERCON ${ }^{\circledR}$ Inertia Emulation [25].

The objective of the synthetic inertia control is "to extract the stored inertial energy from the moving part on WTGs" [26]. There are several versions of synthetic inertia controllers; however they can be classified in two main approaches: (a) Releasing "hidden" inertia and (b) Reserve capacity in pitch. In this paper the hidden inertia approach is considered and it is named synthetic inertia from here.

Synthetic inertia concept allows a controller to the take the kinetic energy from a WT rotating mass. This controller is well-explained in several publications [8], [13], [27]. It is control loop that increases electric power output during the initial stages of a significant downward frequency event. The active power (inertial power, $\Delta P$ ) of the control is achieved by:

$$
\Delta P=2 H_{s y n} \times f_{s y s} \times \frac{d f_{s y s}}{d t}
$$

where $H_{\text {syn }}$ express the synthetic inertia (sec) and $f_{\text {sys }}$ system frequency (p.u). Implementation of synthetic inertia controller is depicted on Figure 1.

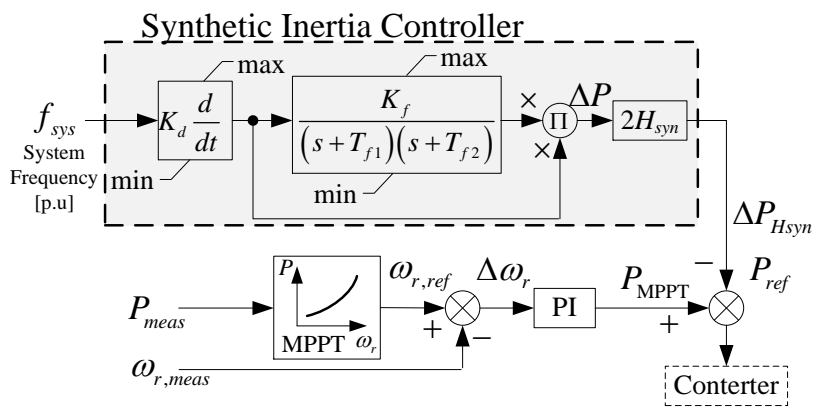

Figure 1. Representative diagram of Maximum Power point Tracking controller and Synthetic Inertia Controller (shadowed) [1].

Several publications relate the main aspects about synthetic inertia [28], [26]; however, there is not a paper that formally discusses the trigger mechanism to activate the synthetic inertia controller. Three activation schemes are presented and discussed in this paper:

\section{A. Scheme I: Continuously Operating}

This is the approach assumed in several publications [15], [7], however is unrealistic. Many publications assume there is not a triggering mechanism for the synthetic inertia controller, in fact, it means the inertia controller receives continuously a system frequency measurement $\left(f_{\text {meas }}\right)$ signal from the $\mathrm{AC}$ system and it is used to derivate the inertial power $(\Delta P)$ using (1) -see Figure 1. This is an unrealistic control scheme because kinetic energy is taken from rotating mass continuously and wind turbine is not allow the recover its kinetic inertia in typical normal operation. However, this scheme is included in this paper only for comparison purposes.

\section{B. Scheme II: Under-frequency Trigger}

This activation scheme uses a trigger controller that produces a trigger signal (ts) based on a comparator. The controller compares the system frequency measurement $\left(f_{\text {meas }}\right)$ with a frequency threshold $\left(f_{a c t}\right)$, the output signal is generated to activate the synthetic inertia controller if system frequency measured is below the action frequency $\left(f_{a c t}\right)$. The activation function of this controller is as follow:

$$
\text { Trigger Signal: } \begin{cases}t s=0 & f_{\text {meas }} \geq f_{\text {act }} \\ t s=1 & f_{\text {meas }}<f_{\text {act }}\end{cases}
$$

\section{Scheme III: Maximum-Frequency Gradient Trigger}

This activation scheme uses a controller that is similar to the typical logic control observed in ROCOF relays. It measures the frequency and calculates $d f / d t$, once the rate of change of frequency exceeds the pre-determined setting $\left(d f / d t_{a c t}\right)$, a trip signal is initiated. The activation function of the maximum-frequency gradient trigger for synthetic inertia is defined by:

Trigger Signal: $\left\{\begin{array}{l|l}t s=0 & \left|\frac{d f_{\text {meas }}}{d t}\right|<\left(\frac{d f}{d t}\right)_{\text {act }} \\ t s=1 & \left|\frac{d f_{\text {meas }}}{d t}\right| \geq\left(\frac{d f}{d t}\right)_{\text {act }}\end{array}\right.$

The $d f / d t_{a c t}$ is threshold that activates the synthetic inertia controller. This approach has been used for years on ROCOF relays and it is used on [29] to activate the synthetic inertia, there is not discussion about its implication on that reference.

\section{SiMULATIONS AND RESULTS}

This section presents simulations and results over a Test System. An equivalent synchronous generator (GS) and loads are used as representative equivalent model of a traditional power system and a small transmission system is included considering two voltage levels -see Figure 3. VSWT using an Electrically Excited synchronous generator (EESG), Type 4$\mathrm{C}$, is used on the simulation for demonstrative purposes. The output of the generator is passed through the full rated power converter to the grid. In this paper, an equivalent model of a cluster of $30 \times 4.5 \mathrm{MW}$ direct-drive EESG is considered (similar characteristic of the Enercon E-112). Figure 4 depicts the general structure of a VSWT the model for the directdrive EESG. This model uses a back-to-back converter, details of all models used can be found on [30], [31], [32]. The parameters used for these models are escalated to simulate an equivalent 4.5 MW wind turbine. DIgSILENT ${ }^{\circledR}$ PowerFactory $^{\mathrm{TM}}[33]$ is used for time-domain simulations and 
DIgSILENT Simulation Language (DSL) is used for dynamic modelling [34]. Figure 5, 6, and 7 show the DSL models created for the activation schemes considered in this paper.

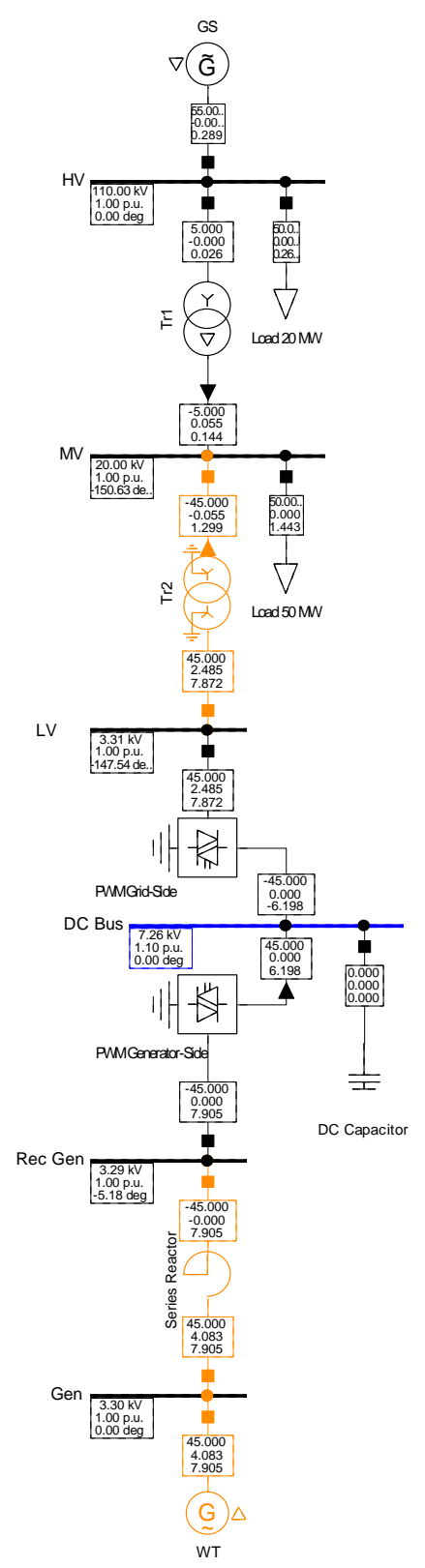

Figure 2. Test System.

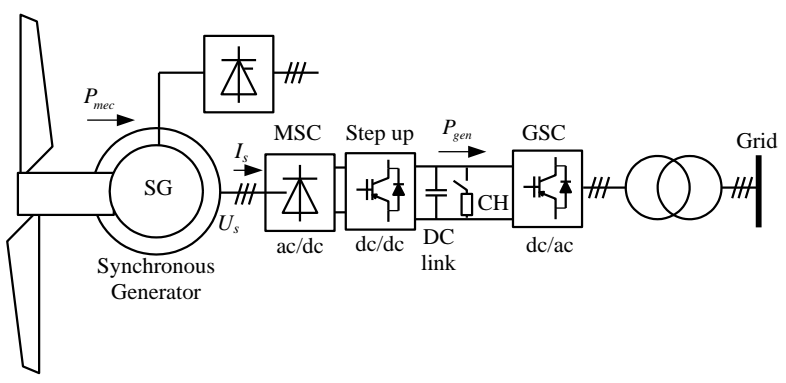

Figure 3. General structure of a variable-speed wind turbine with a directdrive synchronous generator with full-scale frequency converter.

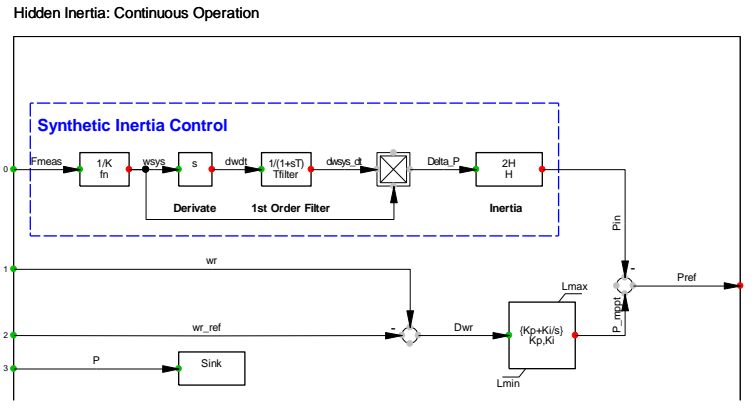

Figure 4. DSL Model Scheme I: Synthetic Inertia Controller using Continuous Operation Scheme for triggering.

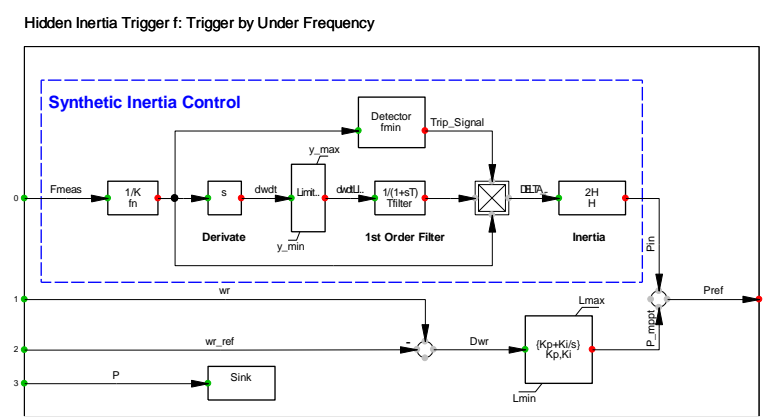

Figure 5. DSL Model Scheme II: Synthetic Inertia Controller using underfrequency trigger.

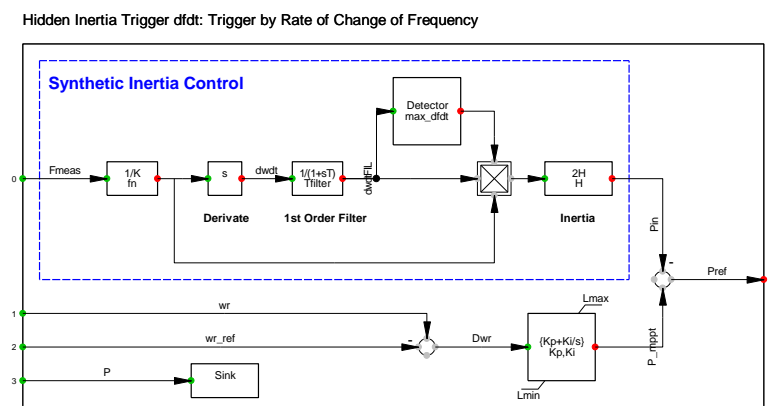

Figure 6. DSL Model Scheme III: Syntehic Inertia Controller considering a ROCOF trigger.

Plots of electromechanical variables on the traditional power system (equivalent synchronous generator-GS) side and wind farm side are shown on Figure 7 and 8 respectively. The activation scheme based on continuously merriment signal (Scheme $I$ ) is the only scheme that includes a negligible time delay on the activation of synthetic inertia, it is an expected result because the control scheme is acting continuously to any frequency change. The small time delay found on the response is provided by the first order filter used to remove the noise amplification on the derivate of the measured frequency.

Activation Scheme II and III require activation condition must be satisfied before activate the synthetic inertia controller, and it depends on the whole system frequency response where the characteristics of the traditional power system (equivalent synchronous generator) has impact on the dynamic performance. 


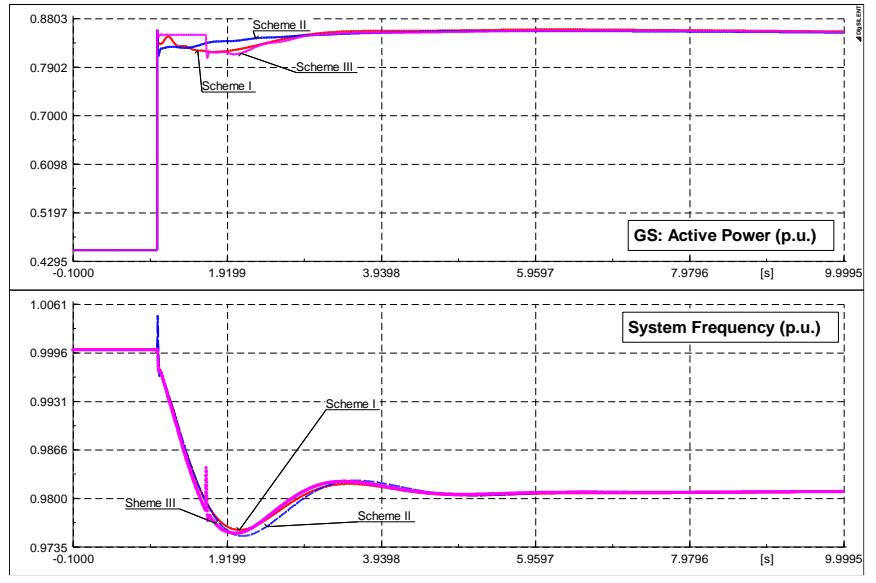

Figure 7. Grid Side: Simulation Results

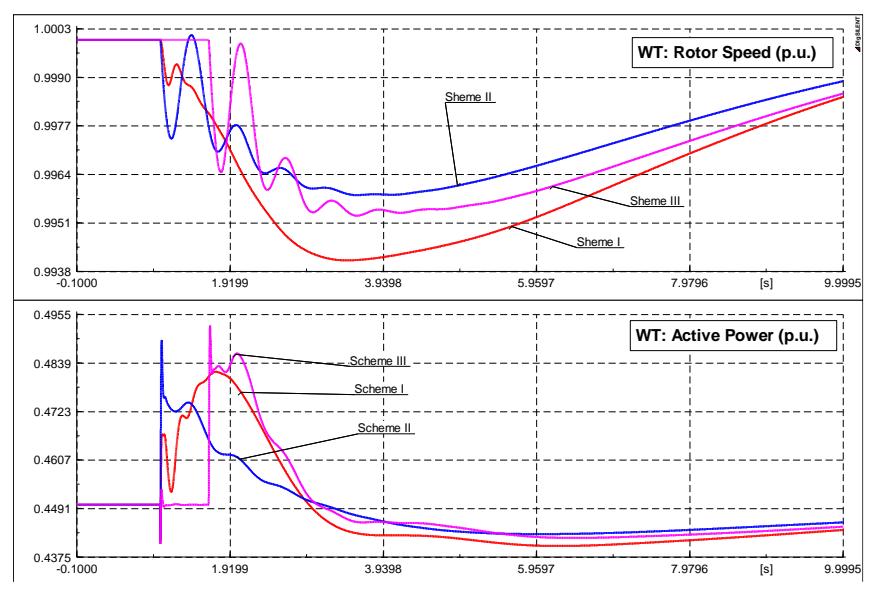

Figure 8. Wind Farm Side: Simulation Results

Simulation results show the under-frequency trigger activation (Scheme II) produces the second faster activation time $\left(t_{a} \sim 2 \mathrm{msec}\right)$ after the frequency disturbance detection $\left(f_{a c t}\right.$ $=0.998$ p.u.). The activation time for maximum-frequency gradient trigger is the longest ( $t_{a} \sim 450 \mathrm{msec}$ ), it is because the $d f / d t$ depends on the total system inertia and for the tests system considered this value is extremely highly compared with the system inertia provided by the controller $\left(H_{s y s}=0.25\right.$ sec). Details about activation time and inertial power $(\Delta P)$ contribution are shown on Figure 10. Inertial power provided by the activation Scheme III is the largest and it is intrinsically related with the threshold $d f / d t_{a c t}$. The initial peak of inertia power after the activation process is large in all cases and it is caused by the $d f / d t$, however, Scheme II exhibit a larger peak than Scheme I. This initial peak indicates a quick response on releasing large amount of kinetic energy in the rotating masses on the WT caused by the power electronic converter. However, discharge of energy to the grid is only for a short period available, and potential dangerous consequences on the mechanical par must be seriously evaluated.
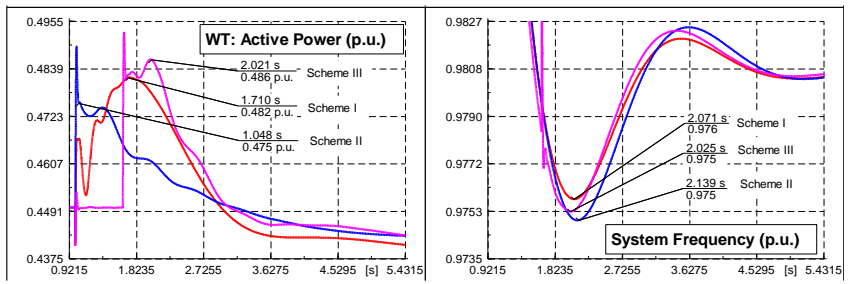

Figure 9. Details of wind farm active power production and system frequency.

The effect of the activation scheme on the rate-of-changeof-frequency and frequency nadir $\left(f_{\min }\right)$ is very important on the system frequency stability. The positive effect of all schemes is shown on Figure 11. The synthetic inertia modifies the $d f / d t$, however, activation Scheme I causes the slower change $\left(f_{\min } \sim 0.976 \mathrm{p} . u\right.$ @ 2.071sec) and Scheme II and Scheme III produces almost the same change on $f_{\min }$ but Scheme III reach the frequency nadir first $\left(t_{\min }=2.025 \mathrm{sec}\right)$ compared with Scheme II $\left(t_{\min }=2.139 \mathrm{sec}\right)$.

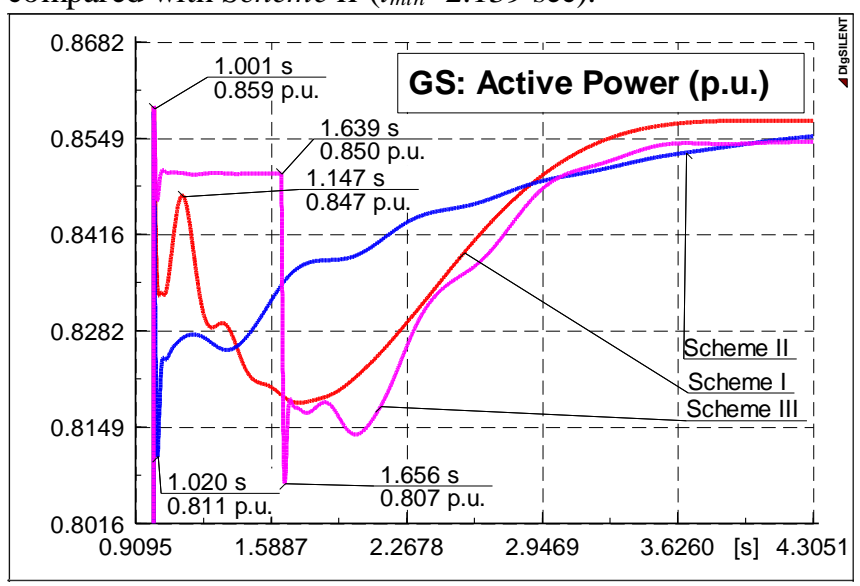

Figure 10. Details of frequency response of the traditional power system side considering the activation schemes.

An important aspect about the impact of activation schemes is the power production of the traditional synchronous generator. The long activation time on the synthetic inertia controller caused by the Scheme III imply traditional generator must quickly react to cope with the system frequency disturbance, that situation makes this activation scheme unpractical in a future electricity network with low inertia. Scheme II produce a fast response and initially reduce the active power solicitation form the traditional generator, however, Scheme II provide the best performance in term of release the requirements of active power from the traditional generators.

\section{CONCLUSION}

This paper proposes three activation schemes for synthetic inertia controller on WTG based on full rated power converters: (i) continuously operating triggering, (ii) underfrequency trigger and (iii) maximum-frequency gradient trigger. Time-domain simulations over a simple test system are used to evaluate the system frequency response 
considering the activations schemes proposed. The main contribution of this paper is the three schemes to activate the synthetic inertia controller and its assessment. Results demonstrate an outstanding system frequency response when the synthetic inertia is activated using the under-frequency trigger. However, further evaluations are required. The author is proposing the under-frequency trigger and maximumfrequency gradient trigger as main activation scheme considering the inertia values on the system to be used.

\section{REFERENCES}

[1] F. Gonzalez-Longatt, "Frequency Control and Inertial Response Schemes for the Future Power Networks," in Large Scale Renewable Power Generation, J. Hossain and A. Mahmud, Eds., ed: Springer Singapore, 2014, pp. 193-231.

[2] F. Gonzalez-Longatt, "Frequency Control and Inertial Response Schemes for the Future Power Networks," in Advances in Technologies for Generation, Transmission and Storage, Green Energy and Technology Series. vol. VIII, J. Hossain and A. Mahmud, Eds., ed Singapur: Springer-Verlag, 2014, p. 363.

[3] F. M. Gonzalez-Longatt, "Effects of the synthetic inertia from wind power on the total system inertia: simulation study," in Environment Friendly Energies and Applications (EFEA), 2012 2nd International Symposium on, 2012, pp. 389-395.

[4] F. Gonzalez-Longatt, "Impact of synthetic inertia from wind power on the protection/control schemes of future power systems: Simulation study," in Developments in Power Systems Protection, 2012. DPSP 2012. 11th International Conference on, 2012, pp. 1-6.

[5] F. Gonzalez-Longatt, "TUTORIAL: Frequency Control and Inertia Response Schemes for the Future Power Networks," presented at the IEEE Inernational Energy Conference and Exhibition, ENERGYCON 2012, Florence, Italy, 2012.

[6] J. Machowski, J. W. Bialek, and J. R. Bumby, Power System Dynamics: Stability and Control, 2nd ed. ed. Oxford: John Wiley, 2008.

[7] J. B. Ekamayake, N. Jenkins, and G. Strbac, "Frequency Response From Wind Turbines," Wind Engineering, vol. 32, pp. 537-586, 2008.

[8] J. Ekanayake and N. Jenkins, "Comparison of the response of doubly fed and fixed-speed induction generator wind turbines to changes in network frequency," Energy Conversion, IEEE Transactions on, vol. 19, pp. 800-802, 2004.

[9] G. Lalor, A. Mullane, and M. O'Malley, "Frequency control and wind turbine technologies," Power Systems, IEEE Transactions on, vol. 20, pp. 1905-1913, 2005.

[10] N. Plc. (2010). National Grid, Grid Code Frequency Response Working Group: "Simulated Inertia". Available: http://www.nationalgrid.com/uk/Electricity/Codes/gridcode/workinggro ups/freqresp/

[11] S. Seman and R. Sakki. (2011). Inertial response - generators and the power electronics. Available: http://www.nrel.gov/wind/systemsintegration/pdfs/2011/active_power control workshop/seman.pdf

[12] GE. (2009). WindINERTIA Control fact sheet. Available: http://www.ge-

energy.com/products and services/products/wind turbines/index.jsp

[13] J. Morren, S. W. H. de Haan, W. L. Kling, and J. A. Ferreira, "Wind turbines emulating inertia and supporting primary frequency control," Power Systems, IEEE Transactions on, vol. 21, pp. 433-434, 2006.

[14] S. Wachtel and A. Beekmann, "Contribution of Wind Energy Converters with Inertia Emulation to frequency control and frequency stability in Power Systems," presented at the 8th International Workshop on Large Scale Integration of Wind Power into Power Systems as well as on Offshore Wind Farms, Bremen, Germany, 2009.

[15] I. Erlich and M. Wilch, "Primary frequency control by wind turbines," in Power and Energy Society General Meeting, 2010 IEEE, 2010, pp. 1-8.

[16] S. Yuan-zhang, Z. Zhao-sui, L. Guo-jie, and L. Jin, "Review on frequency control of power systems with wind power penetration," in
Power System Technology (POWERCON), 2010 International Conference on, 2010, pp. 1-8.

[17] M. Singh, M. Vyas, and S. Santoso, "Using generic wind turbine models to compare inertial response of wind turbine technologies," in Power and Energy Society General Meeting, 2010 IEEE, 2010, pp. 1-7.

[18] R. Doherty, A. Mullane, G. Nolan, D. J. Burke, A. Bryson, and M. O'Malley, "An Assessment of the Impact of Wind Generation on System Frequency Control," Power Systems, IEEE Transactions on, vol. 25, pp. 452-460, 2010.

[19] L. Ruttledge and D. Flynn, "System-wide inertial response from fixed speed and variable speed wind turbines," in Power and Energy Society General Meeting, 2011 IEEE, 2011, pp. 1-7.

[20] I. Erlich, W. Winter, and A. Dittrich, "Advanced grid requirements for the integration of wind turbines into the German transmission system," in Power Engineering Society General Meeting, 2006. IEEE, 2006, p. 7 pp.

[21] D. Gautam, L. Goel, R. Ayyanar, V. Vittal, and T. Harbour, "Control Strategy to Mitigate the Impact of Reduced Inertia Due to Doubly Fed Induction Generators on Large Power Systems," Power Systems, IEEE Transactions on, vol. 26, pp. 214-224, 2011.

[22] GB. (2009). Security and Quality of Supply Standard (SQSS). Available:

http://www.nationalgrid.com/uk/Electricity/Codes/gbsqsscode/

[23] N. W. Miller, K. Clark, and M. Shao, "Frequency responsive wind plant controls: Impacts on grid performance," in Power and Energy Society General Meeting, 2011 IEEE, 2011, pp. 1-8.

[24] N. Miller, K. Clark, and R. Walling, "WindINERTIA: Controlled Inertial Response from GE Wind Turbine Generators," presented at the 45th Annual Minnesota Power Systems Conference, Minneapolis, Minnesota, 2009.

[25] S. Wachtel and A. Beekmann, "Contribution of Wind Energy Converters with Inertia Emulation to Frequency Control and Frequency Stability in Power Systems," presented at the 8th International Workshop on Large-Scale Integration of Wind Power into Power Systems as well as on Transmission Networks for Offshore Wind Farms, Bremen, Germany, 2009.

[26] F. Gonzalez-Longatt, "Impact of synthetic inertia from wind power on the protection/control schemes of future power systems: Simulation study," in 11th International Conference on Developments in Power Systems Protection, 2012. DPSP 2012. , 2012, pp. 1-6.

[27] G. Ramtharan, J. B. Ekanayake, and N. Jenkins, "Frequency support from doubly fed induction generator wind turbines," Renewable Power Generation, IET, vol. 1, pp. 3-9, 2007.

[28] F. Gonzalez-Longatt, "Effects of the synthetic inertia from wind power on the total system inertia: simulation study," in 2nd International Symposium on Environment Friendly Energies and Applications (EFEA 2012), Northumbria University in Newcastle upon Tyne, UK, 2012, pp. $389-395$.

[29] J. Björnstedt, "Integration of Non-synchronous Generation. Frequency Dynamics," PhD Thesis PhD, Department of Measurement Technology and Industrial Electrical Engineering, Lund University, 2012.

[30] F. Gonzalez-Longatt, "Dynamical Model of Variable Speed WECS: Attend of Simplification," presented at the Proceeding of Fifth International Workshop on Large Scale Integration of Wind Power and Transmission Networks for Offshore Wind Farms, Glasgow, Scotland, 2006.

[31] S. Achilles and M. Poller. Direct drive synchronous machine models for stability assessment of wind farm. Available: http://www.digsilent.de/Consulting/Publications/DirectDrive Modeling .pdf

[32] F. González-Longatt, P. Wall, and V. Terzija, "A Simplified Model for Dynamic Behavior of Permanent Magnet Synchronous Generator for Direct Drive Wind Turbines," in IEEE PES Trondheim PowerTech 2011, Trondheim, Norway, 2011.

[33] DIgSILENT, "DIgSILENT PowerFactory," 14.0.524.2 ed. Gomaringen, Germany, 2011.

[34] F. Gonzalez-Longatt and J. Rueda, PowerFactory Applications for Power System Analysis: Springer-Verlag, 2014. 